\title{
Increase in invasive disease caused by Haemophilus influenzae b, the Netherlands, 2020 to 2021
}

Anneke Steens ${ }^{1}$, Kamelia R Stanoeva ${ }^{1,2}$, Mirjam J Knol ${ }^{1}$, Rob Mariman ${ }^{1}$, Hester E de Melker ${ }^{1}$, Nina M van Sorge ${ }^{3,4}$

1. Centre for Infectious Disease Control, National Institute for Public Health and the Environment (RIVM), Bilthoven, the Netherlands

2. European Public Health Microbiology Training Programme (EUPHEM), European Centre for Disease Prevention and Control (ECDC), Stockholm, Sweden

3. Department of Medical Microbiology and Infection Prevention, Amsterdam UMC, location AMC, University of Amsterdam, Amsterdam, the Netherlands

4. Netherlands Reference Laboratory for Bacterial Meningitis, Amsterdam UMC, location AMC, University of Amsterdam, Amsterdam, the Netherlands

Correspondence: Anneke Steens (anneke.steens@rivm.nl)

Citation style for this article:

Steens Anneke, Stanoeva Kamelia R, Knol Mirjam J, Mariman Rob, de Melker Hester E, van Sorge Nina M. Increase in invasive disease caused by Haemophilus influenzae b, the Netherlands, 2020 to 2021. Euro Surveill. 2021;26(42):pii=2100956. https://doi.org/10.2807/1560-7917.ES.2021.26.42.2100956

Article submitted on 04 Oct 2021 / accepted on 21 Oct 2021 / published on 21 Oct 2021

The incidence of most respiratory-transmitted diseases decreased during the COVID-19 pandemic as a result of containment measures. In contrast, in the Netherlands we noted an increase in invasive disease caused by Haemophilus influenzae b (Hib) (from < 0.3/100,000 before 2019 to 0.39 and $0.33 / 100,000$ in 2020 and 2021) in vaccinated and unvaccinated age groups. We did not find a change in vaccine effectiveness against Hib invasive disease (effectiveness $>90 \%$ ). We discuss factors that may have contributed to this rise.

Haemophilus influenzae serotype b ( $\mathrm{Hib}$ ) is a vaccinepreventable disease, which has had a fluctuating but low incidence as a result of childhood vaccination. However, we noted an unexpected increase in the Netherlands in 2020 and 2021 in vaccinated and nonvaccinated age groups. As the increase occurred during the COVID-19 pandemic when several other respiratory transmitted diseases decreased, the change in incidence was especially unexpected. The aim of this study was to describe and provide possible explanations for the observed unexpected increase in Hib disease incidence compared to the previous decades.

\section{Increase in Haemophilus influenzae b invasive disease}

Vaccination against Haemophilus influenzae serotype b (Hib) was introduced in the childhood immunisation programme of the Netherlands in 1993. After a prompt decrease, the annual Hib incidence fluctuated but remained below 0.3 cases per 100,000 during the period 1996 to 2019 (Figure 1 panel A). In 2020 and 2021 (extrapolated for 2021, data up to and including August), the overall incidences were 0.39 and 0.33 per 100,000 , respectively. No clear geographical clustering was observed (Figure 2 panel B). Forty per cent of cases occurred in children under the age of 5 years (Figure 3). The incidence in this age group was below 2.6 per 100,000 between 1996 and 2019, although an increasing trend has been observed since 2012 from 0.5 to 1.0 per 100,000 to 2.0 per 100,000 in 2019 . In 2020 and 2021 respectively, the incidence in the age group under 5 years was 3.3 per $100,000(n=28)$ and 2.6 per 100,000 ( $n=15$ within the first 8 months). Although secular trends occur for Hib, the current increase stands out because it coincides with the coronavirus disease (COVID-19) pandemic, during which a decrease in several other respiratory invasive diseases was observed in many countries $[1,2]$. Correspondingly, the incidence of non-type b $\mathrm{H}$. influenzae invasive disease in the Netherlands decreased by $40 \%$ during 2020 and 2021 compared with 2015 to 2019 (Figure 1 panel B). These decreases were probably caused by reduced transmission resulting from COVID-19 containment measures, but changes in referral and testing policy cannot be excluded [3].

\section{Changes in the vaccination schedule}

Changes related to $\mathrm{Hib}$ vaccination in the childhood immunisation programme (Figure 1 panel A) included a change from the pentavalent to a hexavalent composition (DT3aP-HBV/Hib) in 2011 and subsequently a product change to DT5aP-HBV/Hib in 2019. DT3aP$\mathrm{HBV} / \mathrm{Hib}$ and DT5aP-HBV/Hib differ in composition of the carrier compound, adjuvant and length of the Hib component [4]. Finally, from 2020, the $3+1$ schedule with primary doses at the age of 2, 3 and 4 month and a booster dose at 11 months changed to a 2+1 schedule ( 3,5 and 11 months). Children of mothers who have not received maternal vaccination (ca 30\%) or who are born prematurely, follow a $3+1$ schedule with vaccination at 2, 3, 5 and 11 months. 


\section{FIGURE 1}

Incidence of invasive disease caused by Haemophilus influenzae serotype $\mathrm{b}$ in relation to changes in the childhood immunisation programme (A) and disease incidence caused by non-typeable and non-b $H$. influenzae serotypes (B), the Netherlands, $1992-2021^{\text {a }}$

\section{A. Hib incidence related to vaccination schedule}

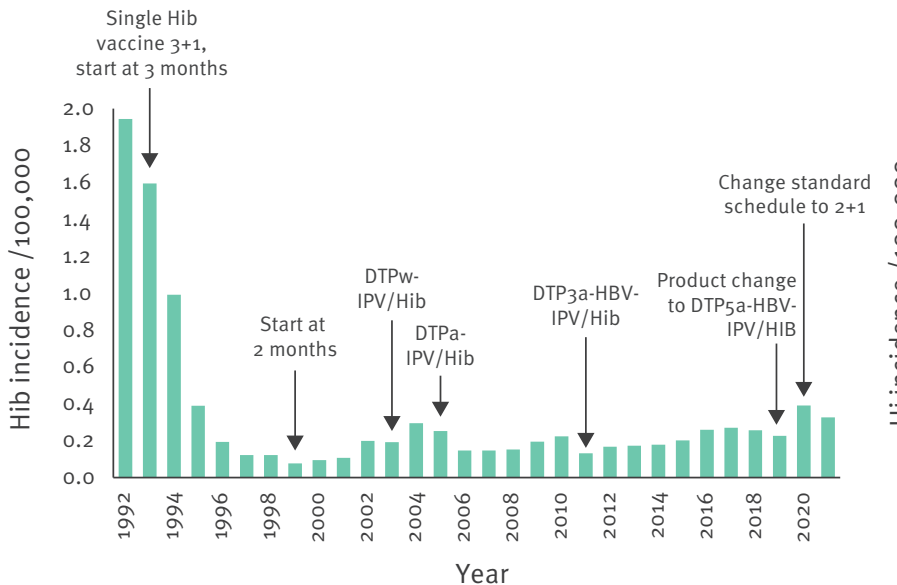

B. Non-b Haemophilus influenzae incidence by serotype

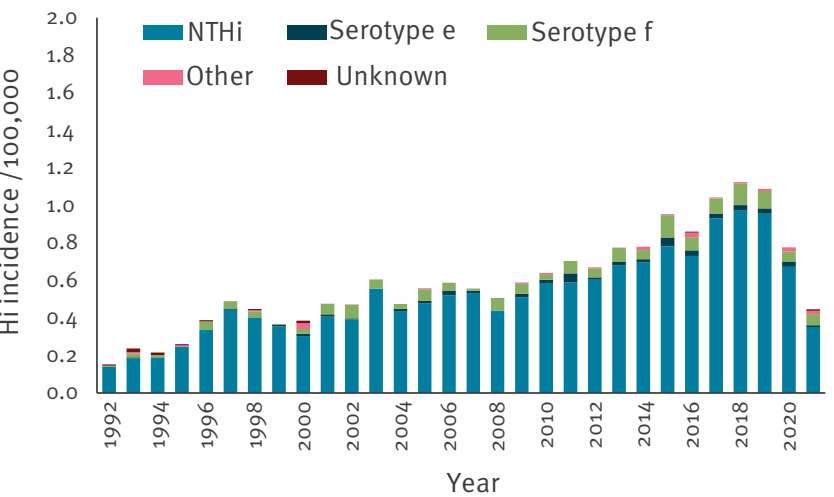

DTPa-IPV/Hib:vaccination against diphtheria, tetanus, pertussis (acellular, component), polio (inactivated) and Hib; DTPw-IPV/Hib: vaccination against diphtheria, tetanus, pertussis (whole cell), polio and Hib; DTP5/3a-HBV-IPV/Hib:vaccination against diphtheria, tetanus, pertussis (acellular, component), hepatitis B, polio (inactivated) and Hib; Hib: Haemophilus influenzae serotype b; NTHi: non-typeable Haemophilus influenzae.

${ }^{a}$ Data for 2021 are extrapolated based on data up to and including August.

\section{FIGURE 2}

Haemophilus influenzae serotype b (Hib) vaccine coverage at municipal level in children born in 2018 (A), Hib incidence at NUTS3-level and geographical distribution of Hib cases $(n=103)$ by vaccine status $(B)$, the Netherlands, January $2020-$ August 2021

A.

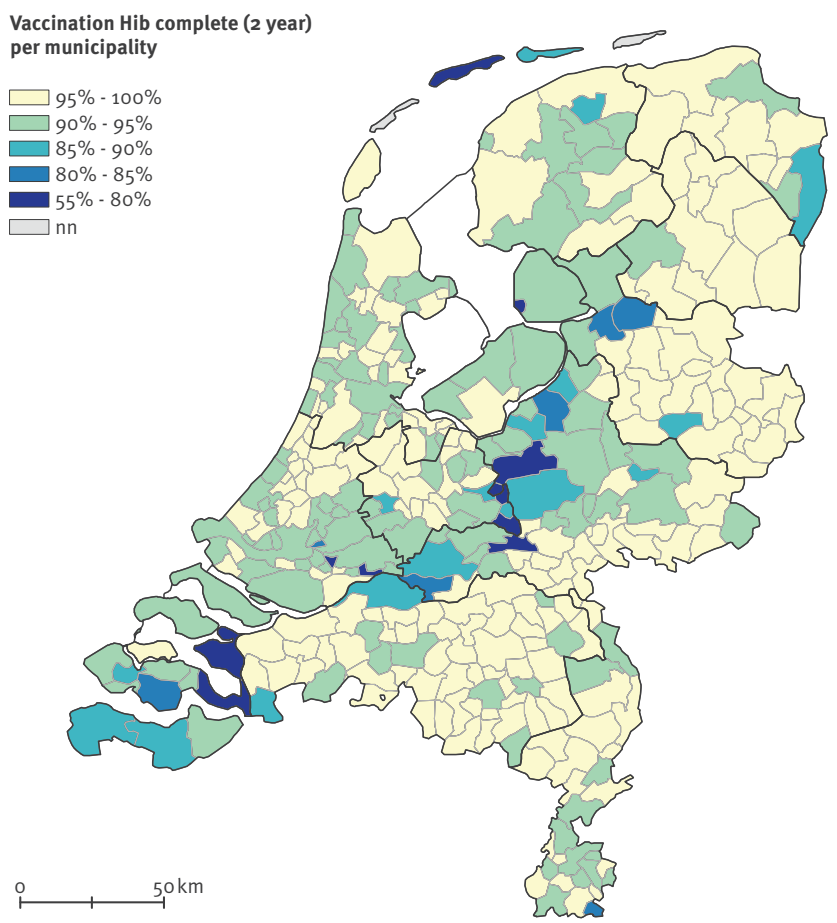

B.

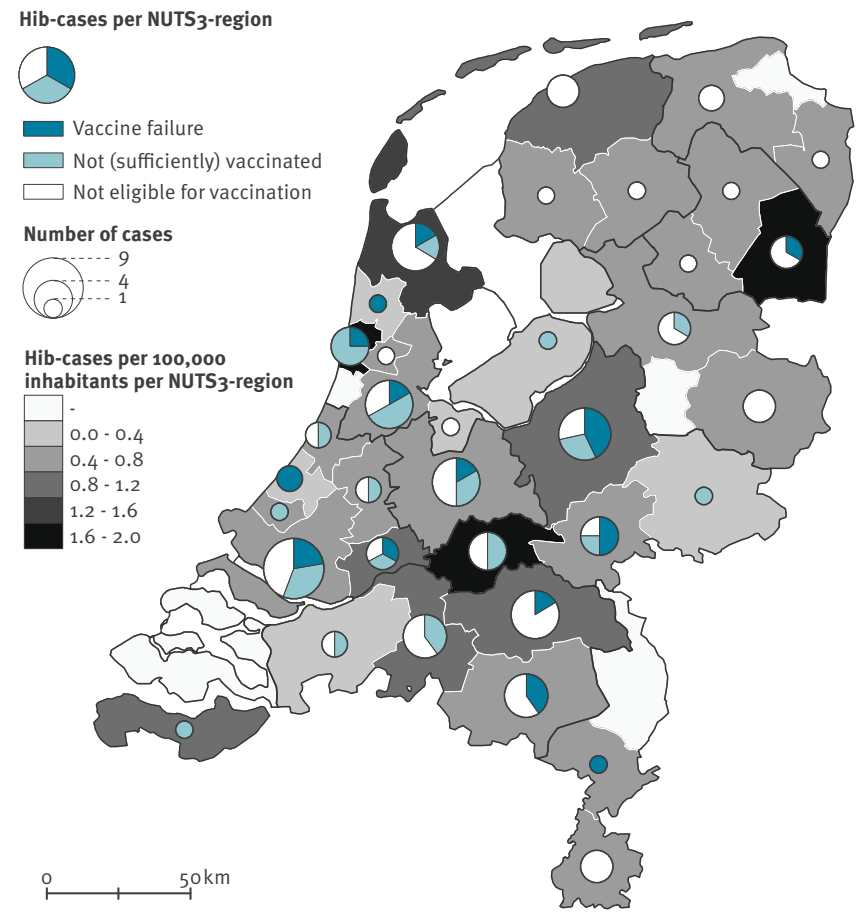

Hib: Haemophilus influenzae serotype b; nn: nomen nescio; NUTS: nomenclature of territorial units for statistics.

Panel A shows the vaccine coverage at 2 years of age in 2020 , i.e. the percentage of fully vaccinated children born in 2018 . For three cases, the postal code was unavailable and they are therefore not presented here. Here, nn indicates that the incidence cannot be shown because of privacy reasons as the municipality is too small to keep confidentiality. 


\section{FIGURE 3}

Age distribution of Haemophilus influenzae serotype b cases, by vaccination status, the Netherlands, January 2020-August $2021(\mathrm{n}=105)$

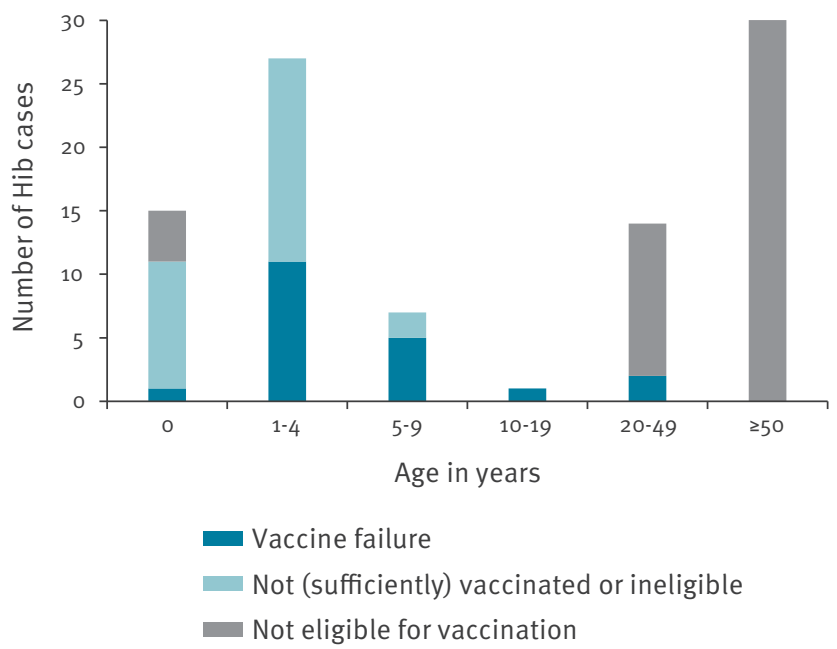

Hib: Haemophilus influenzae serotype b.

Seventeen of the 19 vaccinated cases had received four doses. Note that one case in the age group 1-4 years had unknown vaccine status and is therefore not presented in this figure.

\section{Vaccine failure and effectiveness}

Vaccine failure was defined for thoseyounger than 12 months as a Hib case who had received at least two doses of Hib-containing vaccine. For those 1 year and older, the primary series and a booster at 11 months or at least one dose given after the first birthday counted as vaccine failure. Only doses given more than 14 days before disease onset counted as vaccination.

In 2015 to 2019, on average 9.4 vaccine failures occurred annually (55\% of cases in the vaccine-eligible population, i.e. born in or after April 1993 and older than 3 months). Ten vaccine failures occurred in 2020 and another 10 have so far occurred in 2021 by the end of August (Figure 4). The number of cases in not (sufficiently) vaccinated individuals increased twofold in $2020(n=20)$ compared with the previous 5 years (on average $n=8$ ) and numbers for the first 8 months of 2021 have already reached the 5-year average (Figure 4). Based on the screening method [5] using the population vaccine coverage measured in 2-year-olds [6], the vaccine effectiveness (VE) was estimated at $97 \%$ (95\% confidence interval (CI): 93-99) in 2020 and $91 \%$ (95\% Cl: 78-97) in 2021 compared with $92 \%$ (95\% $\mathrm{Cl}: 88-95)$ in 2015 to 2019. Overall, the VE therefore seems unchanged.

Note that, based on data of the first measles-mumpsrubella (MMR) vaccination [1], some delay in vaccination during the start of the COVID-19 pandemic can also be expected for Hib. However, after catch-up vaccination, participation in the first MMR vaccination only lags $1-2 \%$ behind compared with the year before.

\section{Increase in cases seen both in and outside the Bible Belt}

Although the vaccine coverage for Hib at age 2 years is high in the Netherlands with 93\% [6], there are clustered religious municipalities where vaccine coverage is substantially lower, the so-called Bible Belt (Figure 2 panel A) [7]. We compared the Hib incidence in these municipalities with the rest of the country. Bible Belt communities were selected based on an MMR vaccine coverage lower than $90 \%$ during the period 2015 to 2021. Overall, $9.3 \%$ of the cases $(n=31)$ in the period 2015 to 2021 resided in Bible Belt municipalities. The $\mathrm{Hib}$ incidence was especially high in the Bible Belt in 2020 (1.45/100,000; Figure 5) but the incidence outside the Bible Belt was also higher in 2020 and 2021 (0.35 and $0.32 / 100,000$, respectively, compared with 0.17 and $0.27 / 100,000$ in 2015-2019).

\section{Ethical statement}

In accordance with Dutch law, approval from a medical ethics committee was not deemed necessary since cases were not subject to any actions or rules of conduct. Data regarding cases were obtained by use of standard surveillance procedures, and pseudonymised data were used in the study. Informed consent was not obtained, as the collection of data complies with the exceptions for not asking informed consent as formulated in the Dutch Implementation Act General Data Protection Regulation.

\section{Discussion}

The increase in Hib incidence may be explained by methodological, behavioural, biological or vaccinerelated factors. Changes in surveillance method could affect the detected number of cases. In the Netherlands, all $H$. influenzae isolated from normally sterile sites are submitted for serotyping to the National Reference Laboratory for Bacterial Meningitis (NRLBM) on a voluntary basis. In addition, clinicians or laboratories should notify Hib cases to the municipal health centres. Laboratory and clinical data are merged for surveillance by the National Institute for Public Health (RIVM). This has been the policy for many years. Focused communication on the importance of notification took place in March 2019 [8]. Possible effects of this communication would probably affect the incidence of all $H$. influenzae serotypes as serotyping is only performed by the NRLBM. However, in contrast to the Hib incidence, the incidences of non-b $H$. influenzae serotypes were substantially lower in 2020 and 2021 compared with previous years, despite an increase in non-typeable $H$. influenzae before the COVID-19 pandemic.

The pandemic has changed the pattern of interaction in the society [9]. As suggested by the association between the incidence of COVID-19 hospitalisation and religion [10], the changes in inter-personal interactions 


\section{FIGURE 4}

Number of Haemophilus influenzae serotype b cases in individuals older than 3 months and born in or after April 1993, by vaccine status, and estimated vaccine effectiveness (screening method), the Netherlands, 2003 to 2021 ( $\mathrm{n}=290)$

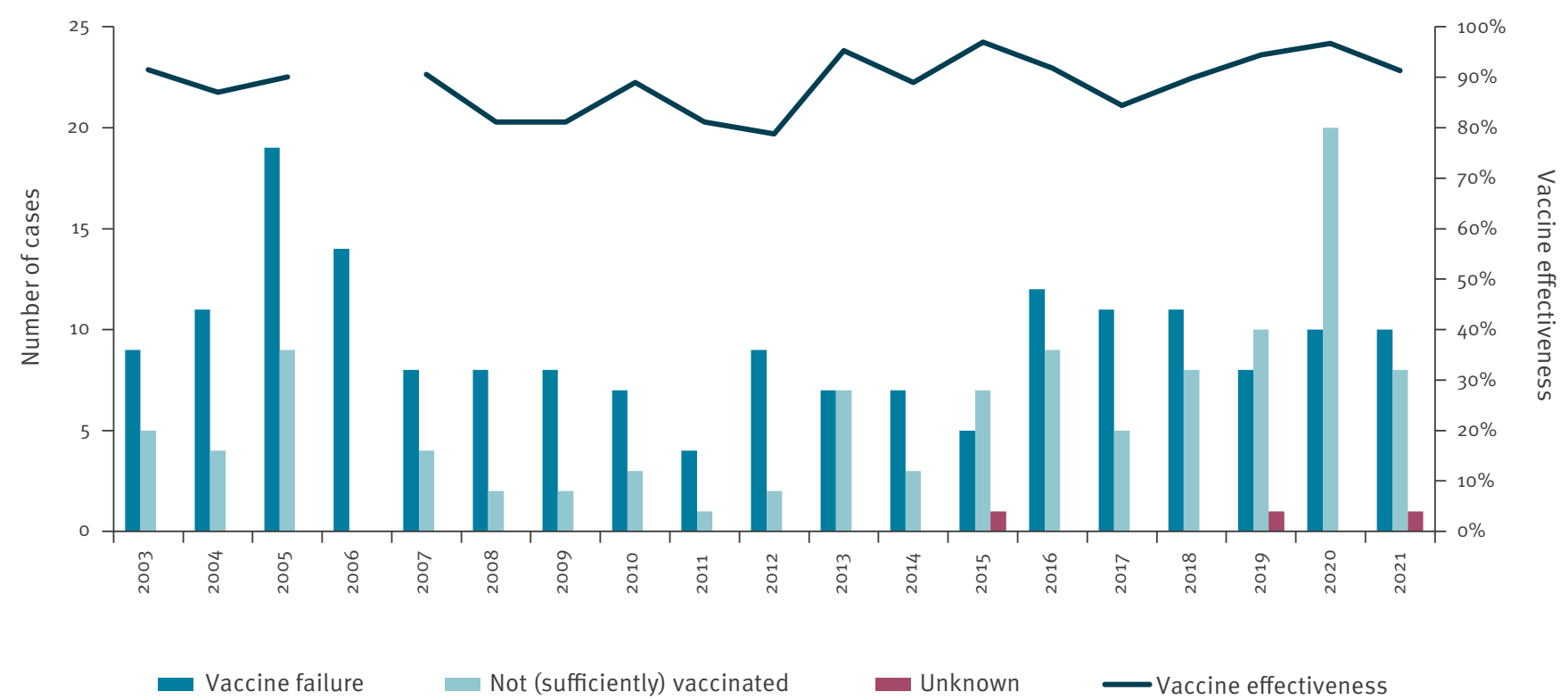

The numbers for 2021 only include data until and including August. It is expected that the number for the entire year will still increase. In 2006, all cases were sufficiently vaccinated, i.e. vaccine failures; therefore, vaccine effectiveness could not be estimated.

\section{FIGURE 5}

Haemophilus influenzae serotype b occurrence in and outside the Bible Belt, the Netherlands, 2015 to 2021 (n = 312)

\section{A. Incidence}

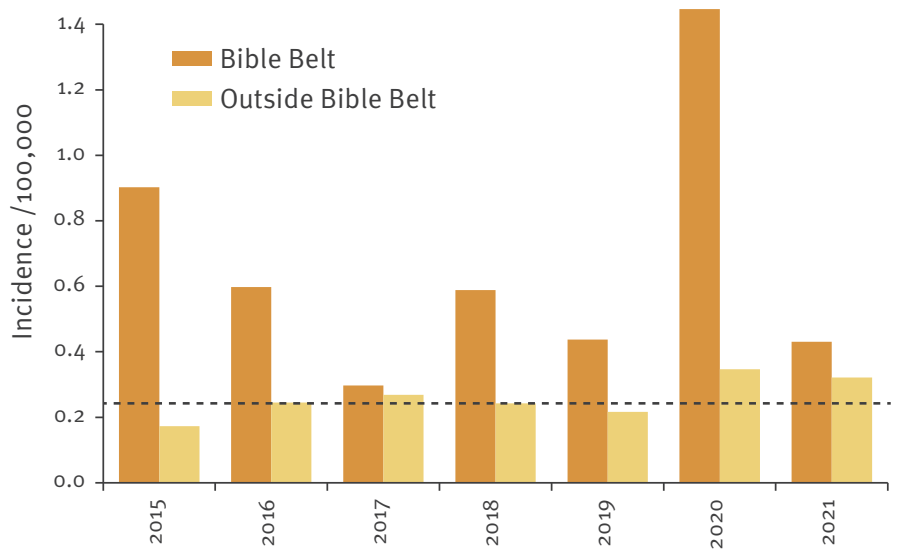

\section{B. Number of cases by vaccine status and region}

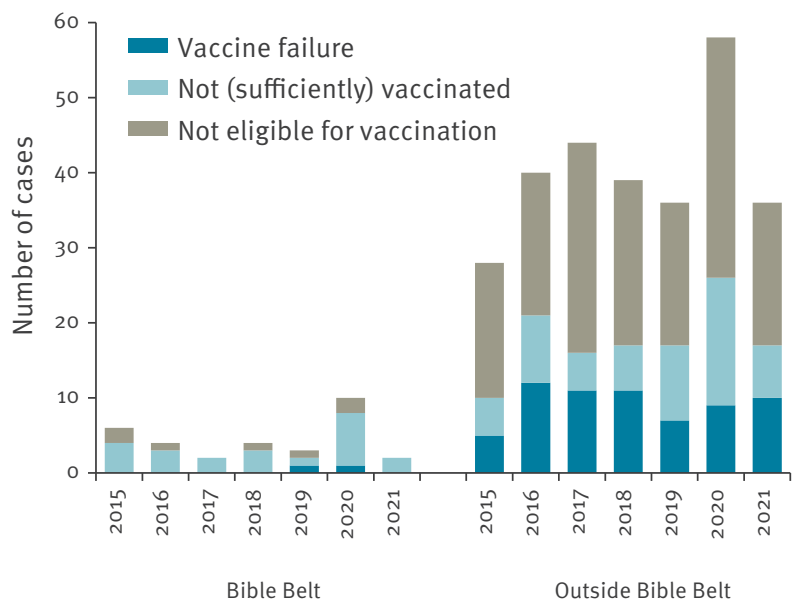

The incidence of 2021 is extrapolated from the first 8 months of the year. Dotted line: average incidence in the Netherlands during $2015-2019$.

and possibly adherence to guidelines may have been different in the Bible Belt vs the rest of the country. Such differences may explain the high percentage of unvaccinated cases in 2020 but not the increase in incidence in and outside the Bible Belt.

The increase in $\mathrm{Hib}$ in vaccinated and unvaccinated age groups may be explained by increased transmission, e.g. because of increased colonisation or by increased invasiveness. Generally, Hib vaccination in childhood immunisation programmes has resulted in very low Hib colonisation rates $[11,12]$. Our recent data show a shift in the incidence of subcluster A within the most prevalent sequence type (ST-6) among invasive Hib isolates [13]. The subclusters were determined using principle component analysis on core genome multilocus sequence typing of 80 isolates from 1986 to 2018. Preliminary data reveal a further expansion of this subcluster in 
2019 to 2021 (data not shown). Whether this dominant clone is a more efficient coloniser or has more invasive traits is currently being investigated. We are planning to study whether the prevalence of asymptomatic Hib colonisation and ST- 6 subcluster A colonisation in children has changed over time. Although preliminary, this clone seems not to be a vaccine escape variant (data not shown).

Overall, the data presented here do not indicate a change in Hib VE. However, immunogenicity studies show lower systemic titres of IgG anti-polyribosylribitol phosphate after booster vaccination with DT5aP-HBV/ Hib compared with DT3aP-HBV/Hib, for both a $2+1$ and a 3+1 schedule [14]. In addition, seroprevalence data from France indicate that a 3+1 immunisation schedule induces a more robust immune response than a $2+1$ schedule [15]. Therefore, we are planning to update previous VE analyses [16], including product- and schedule-specific analyses for different times since vaccination.

\section{Conclusion}

Although the absolute number of invasive Hib cases is still low, the increase in incidence is worrisome because of the severity of the disease. It calls for an explanation in order to implement control measures if needed. Furthermore, this underlines the importance of a comprehensive $H$. influenzae surveillance system including data on serotype and vaccination status.

\section{${ }^{\star}$ Erratum}

Figure 5 was originally published without the line showing the average incidence in panel $A$, and without the captions under the $\mathrm{x}$ axis in panel $\mathrm{B}$. This was corrected on 28 October 2021. We apologise for the mistake.

\section{Acknowledgements}

We would like to thank Silvia Herrera Leon of the European Public Health Microbiology Training Programme for reviewing the manuscript. Furthermore, we want to acknowledge Ben Bom of the National Institute for Public Health and the Environment for creating the maps shown in Figure 2.

\section{Conflict of interest}

N.M.v.S received consultancy fees from Pfizer, MSD, and GSK outside the submitted work (fees paid to Amsterdam UMC); In addition, N.M.v.S has a patent WO 2013/020090 A3 not related to the submitted work with royalties paid to University of California San Diego. All other authors report no potential conflicts of interest.

\section{Authors' contributions}

A.S., M.J.K., H.E.d.M and N.M.v.S. conceived and designed the study. A.S., M.J.K, R.M. and N.M.v.S. were involved in data collection. A.S. and K.R.S. performed data analysis. A.S. made the figures and drafted the manuscript. All authors interpreted the data, critically reviewed the manuscript, and approved the final version.

\section{References}

1. Middeldorp M, van Lier A, van der Maas N, Veldhuijzen I, Freudenburg W, van Sorge NM, et al. Short term impact of the COVID-19 pandemic on incidence of vaccine preventable diseases and participation in routine infant vaccinations in the Netherlands in the period March-September 2020 Vaccine. 2021;39(7):1039-43. https://doi.org/10.1016/j. vaccine.2020.12.080 PMID: 33478793

2. Brueggemann $A B$, Jansen van Rensburg MJ, Shaw D, McCarthy ND, Jolley KA, Maiden MCJ, et al. Changes in the incidence of invasive disease due to Streptococcus pneumoniae, Haemophilus influenzae, and Neisseria meningitidis during the COVID-19 pandemic in 26 countries and territories in the Invasive Respiratory Infection Surveillance Initiative: a prospective analysis of surveillance data. Lancet Digit Health. 2021;3(6):e360-70. https://doi.org/10.1016/S25897500(21)00077-7 PMID: 34045002

3. Dirkx KKT, Mulder B, Post AS, Rutten MH, Swanink CMA, Wertheim HFL, et al. The drop in reported invasive pneumococcal disease among adults during the first COVID-19 wave in the Netherlands explained. Int J Infect Dis. 2021;111:196-203. https://doi.org/10.1016/j.ijid.2021.08.060 PMID: 34455081

4. Kelly DF, Moxon ER, Pollard AJ. Haemophilus influenzae type b conjugate vaccines. Immunology. 2004;113(2):163-74. https:// doi.org/10.1111/j.1365-2567.2004.01971.x PMID: 15379976

5. Hahné S, Bollaerts K, Farrington P. Vaccination programmes. Epidemiology, monitoring, evaluation. Abingdon-on-Thames: Routledge; 2021. ISBN 9781138054851.

6. van Lier EA, Oomen PJ, Giesbers H, van Vliet H, Hament $H-M$, Drijfhout IH, et al. Vaccinatiegraad en jaarverslag Rijksvaccinatieprogramma Nederland 2020. [Immunisation coverage and annual report National Immunisation Programme in the Netherlands 2020]. Bilthoven: National Institute for Public Health and the Environment; 2021. Dutch. Available from: https://www.rivm.nl/publicaties/vaccinatiegraad-enjaarverslag-rijksvaccinatieprogramma-nederland-2020

7. Ruijs WL, Hautvast JL, van der Velden K, de Vos S, Knippenberg $\mathrm{H}$, Hulscher ME. Religious subgroups influencing vaccination coverage in the Dutch Bible belt: an ecological study. BMC Public Health. 2011;11(1):102. https://doi.org/10.1186/14712458-11-102 PMID: 21320348

8. van den Boogaard J, van der Ende A, Westerhof A, Ruijs WLM, de Melker HE, Knol MJ. Voldoen medisch microbiologische laboratoria en de GGD aan de landelijke meldingsplicht voor invasieve Hib-ziekte? [Do medical microbiological laboratories and the municipal health services comply with the national reporting obligation for invasive Hib disease?]. Infectieziekten Bulletin. 2019;30(2). Dutch. Available from: https://magazines. rivm.nl/2019/03/infectieziekten-bulletin/voldoen-medischmicrobiologische-laboratoria-en-de-ggd-aan-de

9. Backer JA, Mollema L, Vos ER, Klinkenberg D, van der Klis FR, de Melker HE, et al. Impact of physical distancing measures against COVID-19 on contacts and mixing patterns: repeated cross-sectional surveys, the Netherlands, 2016-17, April 2020 and June 2020. Euro Surveill. 2021;26(8). https:// doi.org/10.2807/1560-7917.ES.2021.26.8.2000994 PMID: 33632374

10. Vermeer P, Kregting J. Religion and the transmission of COVID-19 in the Netherlands. Religions (Basel). 2020;11(8):393. https://doi.org/10.3390/rel11080393

11. Giufrè M, Daprai L, Cardines R, Bernaschi P, Ravà L, Accogli M, et al. Carriage of Haemophilus influenzae in the oropharynx of young children and molecular epidemiology of the isolates after fifteen years of $\mathrm{H}$. influenzae type $\mathrm{b}$ vaccination in Italy. Vaccine. 2015;33(46):6227-34. https://doi.org/10.1016/j. vaccine.2015.09.082 PMID: 26440924

12. Shrestha S, Stockdale LK, Gautam MC, Gurung M, Feng $\mathrm{S}$, Maskey P, et al. Impact of vaccination on haemophilus influenzae type b carriage in healthy children less than 5 years of age in an urban population in Nepal. J Infect Dis. 2021;224(Supplement 3) Supplement 3;S267-74. https://doi. org/10.1093/infdis/jiabo72 PMID: 34469554

13. Schurink-van 't Klooster TM, de Melker HE, editors. The National Immunisation Programme in the Netherlands. Surveillance and developments in 2019-2020. Bilthoven National Institute for Public Health and the Environment 2020. Available from: https://www.rivm.nl/bibliotheek/ rapporten/2020-0077.pdf

14. Knuf M, Haas H, Garcia-Corbeira P, Turriani E, Mukherjee P, Janssens W, et al. Hexavalent vaccines: What can we learn from head-to-head studies? Vaccine. 2021;39(41):6025-36. https:// doi.org/10.1016/j.vaccine.2021.08.086 PMID: 34531081

15. Hong $E$, Terrade $A$, Denizon $M$, Aouiti-Trabelsi $M$, Falguières M, Taha MK, et al. Haemophilus influenzae type b (Hib) seroprevalence in France: impact of vaccination schedules. 
BMC Infect Dis. 2021;21(1):715. https://doi.org/10.1186/

S12879-021-06440-w PMID: 34330228

16. Monge S, Hahné SJ, de Melker HE, Sanders EA, van der Ende A, Knol MJ. Effectiveness of the DTPa-HBV-IPV/Hib vaccine against invasive Haemophilus influenzae type b disease

in the Netherlands (2003-16): a case-control study. Lancet Infect Dis. 2018;18(7):749-57. https://doi.org/10.1016/S14733099(18)30166-X PMID: 29752131

\section{License, supplementary material and copyright}

This is an open-access article distributed under the terms of the Creative Commons Attribution (CC BY 4.0) Licence. You may share and adapt the material, but must give appropriate credit to the source, provide a link to the licence and indicate if changes were made.

Any supplementary material referenced in the article can be found in the online version.

This article is copyright of the authors or their affiliated institutions, 2021. 